\title{
El expediente de protección de las bodegas de Sanlúcar de Barrameda
}

Por encargo de la Delegación Provincial de Cultura de la Junta de Andalucía en Cádiz iniciamos en septiembre de 2007 -José Manuel Aladro Prieto, arquitecto, y el que esto suscribe- el expediente de catalogación genérica colectiva de los espacios bodegueros de Sanlúcar de Barrameda. Asumimos el compromiso profesional con gran interés, entusiasmo y, por qué no decirlo, cariño y responsabilidad. La tarea se antojaba ardua y dificultosa.

El ingente volumen de bienes inmuebles que se enmarcan dentro de este conjunto patrimonial -149 referencias catastrales identificadas que aglutinan alrededor de unos 200 cascos de bodegas-, la fuerte especulación inmobiliaria a la que están sometidos, su acelerada desaparición, el escaso, cuando no nulo, grado de protección del que gozan en los planeamientos municipales y/o autonómicos, la suspicacia y reticencia que nuestras pesquisas levantaban entre muchos de los propietarios con los consecuentes problemas de accesibilidad que esto ha provocado $y$, por último, la urgencia con la que se hace necesario intervenir han sido los condicionantes bajo los que hemos desarrollado nuestro trabajo.

La metodología empleada ha sido diversa y acorde a la complejidad del conjunto patrimonial objeto del estudio. La web del Aula de Investigación Histórica Gerión (www.gerionsanlucar.com), colectivo fuertemente implicado en la defensa del patrimoio sanluqeño, nos ayudó sobremanera a la hora de tomarle el pulso a la situación.

Procedimos después al vaciado de bibliografía especializada tanto en arquitectura bodeguera como en aspectos históricos, sociales y culturales asociados a Sanlúcar de Barrameda y a su vinicultura. Consultamos también cartografia, fotografia aérea y planimetría de inmuebles y conjuntos bodegueros concretos. Esto, junto a las colecciones fotográficas y los grabados históricos, nos ha permitido rastrear la evolución y modificaciones que han experimentado las construcciones bodegueras, la relación que éstas mantienen con el resto del conjunto urbano, las áreas donde tradicionalmente se han localizado, asi como los cambios de ubicación que esta actividad productiva ha experimentado.

Pero sin duda alguna, la información más valiosa nos la han ofrecido las visitas -más de treinta- realizadas al campo de trabajo. Para ello, partimos de la parcelación establecida en el Documento de Avance de la Revisión-adaptación del PGOU de Sanlúcar de Barrameda de Septiembre 2006. En un primer acercamiento, nos dedicábamos a observar y analizar el exterior de los complejos bodegueros -su estado de conservación, uso que reciben en la actualidad, relación que mantienen con los edificios circundantes- para posteriormente concertar visitas con los propietarios y acceder al interior de los distintos cascos. Desafortunadamente esto no ha sido posible en todos los casos ya que nos hemos encontrado con inmuebles en desuso, algunos en avanzado estado de derrumbamiento, a cuyos propietarios no hemos logrado localizar.

Durante estas visitas tomamos fotografias tanto de exteriores como de interiores que, junto a las descripciones de los inmuebles, las fotografias aéreas y los planos de las parcelas catastrales conforman las fichas que incluimos en el informe final que estamos ultimando. Además, con objeto de dotar a este inventario de una sólida justificación etnográfica, realizamos paralelamente entrevistas no formalizadas y abiertas a bodegueros, empleados y otros miembros de la población local ajenos al sector con la intención de obtener información privilegiada sobre saberes productivos, procesos de transmisión y sociabilidad, dimensión simbólica, identitaria y económica de la actividad, etc.

La especial relevancia de la arquitectura bodeguera en la configuración del entramado urbano sanluqueño da muestras de la vocación vinícola de esta localidad así como de la importancia y arraigo que esta actividad productiva ha tenido para la economía de la zona. Hemos podido contrastar, no obstante, cómo el sector vinicola, sin dejar de ser importante, ha perdido centralidad económica a favor de otras actividades. Ello explica el pesimismo generalizado que existe con respecto al futuro del sector bodeguero y de la arquitectura asociada a él. A modo de metáfora, esta diversificación en las fuentes de ingreso tiene también su reflejo en el desplazamiento hacia el extrarradio que algunas de las firmas bodegueras más emblemáticas viene experimentando en los últimos años. Obviamente, la búsqueda de mayor operatividad y funcionalidad en las nuevas instalaciones ha inspirado también estas estrategias empresariales.

A nivel simbólico, el caso de Sanlúcar de Barrameda resulta paradigmático ya que, a pesar de que en esta localidad se elaboran los vinos genéricos del Marco del Jerez, se produce una identificación de gran calado entre un tipo especifico, la manzanilla, y esta población, que opera tanto en el interior como en el exterior de la misma. Por encima de la fuerte estratificación social que la industria bodeguera de esta zona ha generado y en base al especifico y exclusivo origen local de la manzanilla, este vino se constituye en "patrimonio común de todo el pueblo" de Sanlúcar (GÓMEZ DíAZ, Ana Maria: La Manzanilla. Historia y Cultura. Las bodegas de Sanlúcar. Sanlúcar de Barrameda. Pequeñas ideas editoriales, 2002) llegando a impregnar prácticamente todas las esferas de la vida cotidiana: ciclo festivo -Feria de la Manzanilla, Carreras de Caballos en Bajo Guía-, gastronomia, ámbitos de sociabilidad...

Así, son interesantes las pautas de consumo, diferentes, al menos en parte, a las apreciadas en otras localidades del Marco. Por ejemplo, la venta a granel extendida y generalizada incluso entre las firmas más potentes del sector, el uso de utensilios y elementos característicos como la venencia de caña, los vasos de caña en bandejita metálica que se utilizan para la manzanilla en vez del catavino, el empleo de una terminología propia, etc. Pero quizás el ejemplo más claro de la importancia que posee la manzanilla a nivel simbólico e identitario lo encontremos en la personificación, la feminización para ser más exactos, de la que es objeto este vino. Tanto los nombres comerciales que se le atribuyen como las representaciones, ilustraciones o personajes históricos con los que se asocia forman parte del universo femenino.

También hemos encontrado peculiaridades significativas en el plano arquitectónico. Por ejemplo hemos detectado en las bodegas sanluqueñas una mayor presencia de elementos metálicos, una mayor profusión en el uso del hierro y de elementos decorativos y ornamentales que se toman, en muchos casos, de la arquitectura popular. Otras soluciones arquitectónicas observadas han sido las cerchas de madera utilizadas para salvar grandes luces, los bajetes de piedra ostionera que se utilizan como soporte de las botas, o las puertas de rastrillo que comunican unos cascos de bodega con otros. Por último habría también que comentar que en Sanlúcar se produce una curiosa simbiosis, una mezcolanza entre distintos espacios "sagrados", por una parte los conventos e iglesias que se convierten en bodegas y por otra las bodegas que recuerdan a catedrales y santuarios.

Confiamos en que este trabajo contribuya de forma integral a la conservación y puesta en valor de este conjunto patrimonial tan característico de la Revolución Industrial Andaluza. Es decir, que no se atienda exclusivamente a su dimensión material, arquitectónica y urbana sino que se contemplen igualmente sus valores simbólicos, identitarios e ideológicos.

\section{Julio de Vega López}

Antropólogo 